\title{
Integrated Intelligent CAD System for Interactive Design, Analysis and Prototyping of Compression and Torsion Springs
}

\author{
Isad Saric $\left(\mathbb{D}\right.$, Enis Muratovic*(-), Adil Muminovic, Adis J. Muminovic $\mathbb{C}^{(}$, Mirsad Colic, Muamer Delic $\mathbb{(}$, \\ Nedim Pervan (1) and Elmedin Mesic (1)
}

check for

updates

Citation: Saric, I.; Muratovic, E.;

Muminovic, A.; Muminovic, A.J.; Colic, M.; Delic, M.; Pervan, N.; Mesic, E. Integrated Intelligent CAD System for Interactive Design, Analysis and Prototyping of Compression and Torsion Springs. Appl. Sci. 2022, 12, 353. https:// doi.org/10.3390/app12010353

Academic Editor: Andrea Paglietti

Received: 26 November 2021

Accepted: 28 December 2021

Published: 30 December 2021

Publisher's Note: MDPI stays neutral with regard to jurisdictional claims in published maps and institutional affiliations.

Copyright: (c) 2021 by the authors. Licensee MDPI, Basel, Switzerland. This article is an open access article distributed under the terms and conditions of the Creative Commons Attribution (CC BY) license (https:/ / creativecommons.org/licenses/by/ $4.0 /)$.
Department of Mechanical Design, Faculty of Mechanical Engineering, University of Sarajevo, 71000 Sarajevo, Bosnia and Herzegovina; saric@mef.unsa.ba (I.S.); muminovic@mef.unsa.ba (A.M.); adis.muminovic@mef.unsa.ba (A.J.M.); colic@mef.unsa.ba (M.C.); delic@mef.unsa.ba (M.D.); pervan@mef.unsa.ba (N.P.); mesic@mef.unsa.ba (E.M.)

* Correspondence: muratovic@mef.unsa.ba

\begin{abstract}
This paper presents the development and implementation of integrated intelligent CAD (computer aided design) system for design, analysis and prototyping of the compression and torsion springs. The article shows a structure of the developed system named Springs IICAD (integrated intelligent computer aided design). The system bounds synthesis and analysis design phases by means of the utilization of parametric 3D (three-dimensional) modeling, FEM (finite element method) analysis and prototyping. The development of the module for spring calculation and system integration was performed in the C\# (C Sharp) programming language. Three-dimensional geometric modeling and structural analysis were performed in the CATIA (computer aided three-dimensional interactive application) software, while prototyping is performed with the Ultimaker 3.0 3D printer with support of Cura software. The developed Springs IICAD system interlinks computation module with the basic parametric models in such a way that spring calculation, shaping, FEM analysis and prototype preparation are performed instantly.
\end{abstract}

Keywords: integrated intelligent CAD system; springs; parametric 3D modelling; FEM analysis; prototyping; C\#

\section{Introduction}

Springs are one of the most fundamental elements in the wide spectrum of mechanical engineering applications [1]. A spring represents an elastic body whose function is to store strain energy when deflected by the force and return the same amount of energy when being released [2,3]. Traditional spring design has several forms, which are used to perform different functions in various fields of use, such as manufacturing processes, automotive design, electronics, and consumer goods [4]. The design process of springs is based on material characteristics mostly defined by the shear modulus and maximum shear stress of the material, and a series of design parameters such as mean coil diameter, inner and outer coil diameters, wire diameter, and pitch $[5,6]$.

In the recent period, the rapid development of new technologies has brought a new industrial era. The current industrial reform is based on integrating the existing knowledge of the classical design process with the modern manufacturing and production services $[7,8]$. Continuous improvements in the firmly based conventional technologies with introduction to complex knowledge-based systems results in new, higher degree technology implemented in mechanical and manufacturing fields [9-11]. Nowadays, mechanical engineering is becoming a growing domain with an upgraded level of automation and intelligent manufacturing processes which results in a higher degree of parameter control, and the minimization of rejections and errors, i.e., product defects, reduction of unplanned downtimes and improved flexibility [12,13]. As is the case with other mechanical components, spring design is commonly carried out with various tables and charts 
which contain pre-determined specifications. The exact specification of spring quantities is still unknown to a certain extent. Even though spring theory and accumulated practical knowledge have developed over the years, the range of materials, sizes and shapes is so great that the design process represents a severe engineering challenge. Even with the assistance of a computer, designers often need to oversimplify the spring design procedure [14-16]. Computer assistance provides various types of engineering analyses used for design verification. FEM analysis, incorporated in the CAD system, is the most used numerical analysis in practice, as it has reached a high level of sophistication in the calculation capabilities $[17,18]$. The design verification process relies on a valid 3D representation of a product, which can be parametrized in order to achieve variable geometry, i.e., various design solutions. The parametrization procedure interlinks the geometrical sizes of a 3D model with a functional approach. Computer assistance is also reflected in the prototype preparation modules, used for product prototyping which comes in handy for gaining an answer to a specific problem or testing hypothesis [19].

The effect of the spring geometry and corresponding behavior under the applied load is quite an interesting thematic in many branches of science, as many researches consider various factors which can be influenced for the purpose of achieving better spring design [20-22]. However, the spring design process itself requires an establishment of a knowledge-based and intelligent approach which will help engineers not only in a design process but also in decision making. Considering that, a system with an intelligent approach for the spring design is created. This research presents the novel method for spring design via the developed Springs IICAD system.

\section{Materials and Methods}

\subsection{Problem Identification}

Modern product design is defined as a complex creative process. With ever-growing information flow and a level of knowledge needed for solving design problems, a high degree of specialization is required. Computer technologies, having constantly developed and changed from the past up to the present, have become an important and indispensable part in every area of daily life. Used in the mechanical engineering field, computers are also utilized in the design process for various purposes. Contemporary designers need to be trained to work with new tools that meet the high requirements of the design agency, where the application of computers is necessary at all stages. Design stages usually involve two types of tasks: symbolic reasoning (synthesis) and numerical computation (analysis). The current CAD technology is very efficient for the mentioned tasks, especially for graphical presentation, but it lacks when it comes to providing support to the designer. Synthesis has the greatest impact on the production cost and the product quality. Therefore, automatization of the synthesis can improve efficiency and quality of the design process. With the implementation of the object-oriented programming techniques, appropriate support system architecture can be made, for the areas of the design process which are not sufficiently developed [23]. The structure of the Springs IICAD system, developed for the purposes of the spring calculation, design, FEM analysis and prototyping is explained in this article. The system is based on a modular principle, so that designer in interaction with the computer can automatically perform multiple activities. The basic geometry of compression and torsion springs is shown on Figure 1.

Development of the Springs IICAD system required proper knowledge of spring theory [24-26]. Although a mathematical model expresses what is happening inside the spring, there are still many unknowns in this field, so that the spring design problem often relies on the subjectivity of a designer. Although theory has been refined over the years, and many factors have changed as the experience increased, the range of sizes, shapes and materials is so great that theory is stretched to the extremes. Deployment of AI (artificial intelligence) technologies into the existing CAD systems is a very efficient way of implementing an intelligent design workspace that is mainly featured on creativity. The developed Springs IICAD system represents one of the AI techniques called KBS (knowledge-based system), 
meaning ES (expert system), based on knowledge [27-29]. A designer, in an interaction with a computer, can simultaneously conduct multiple activities during the design process of the spring. The architecture of the Springs IICAD system is shown on Figure 2.

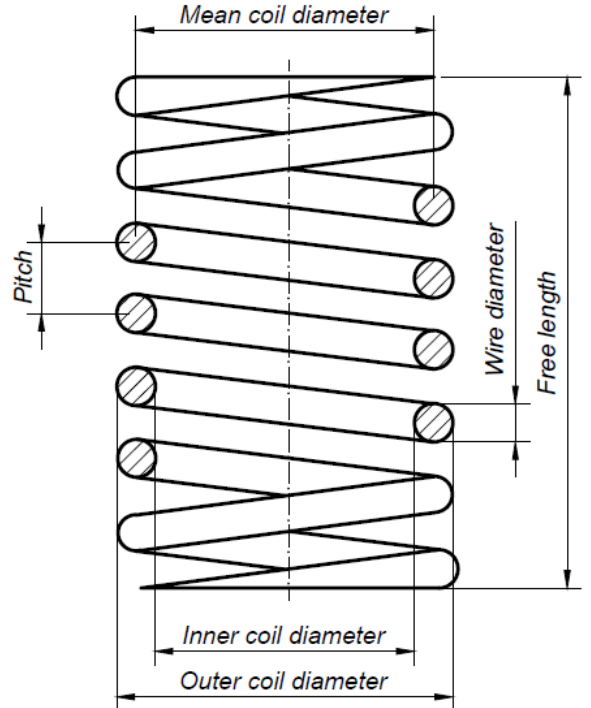

a)

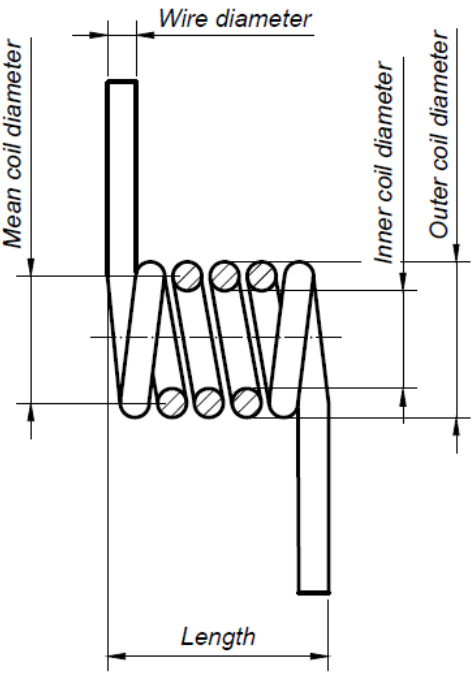

b)

Figure 1. Basic spring geometry. (a): Compression spring, (b): Torsion spring.

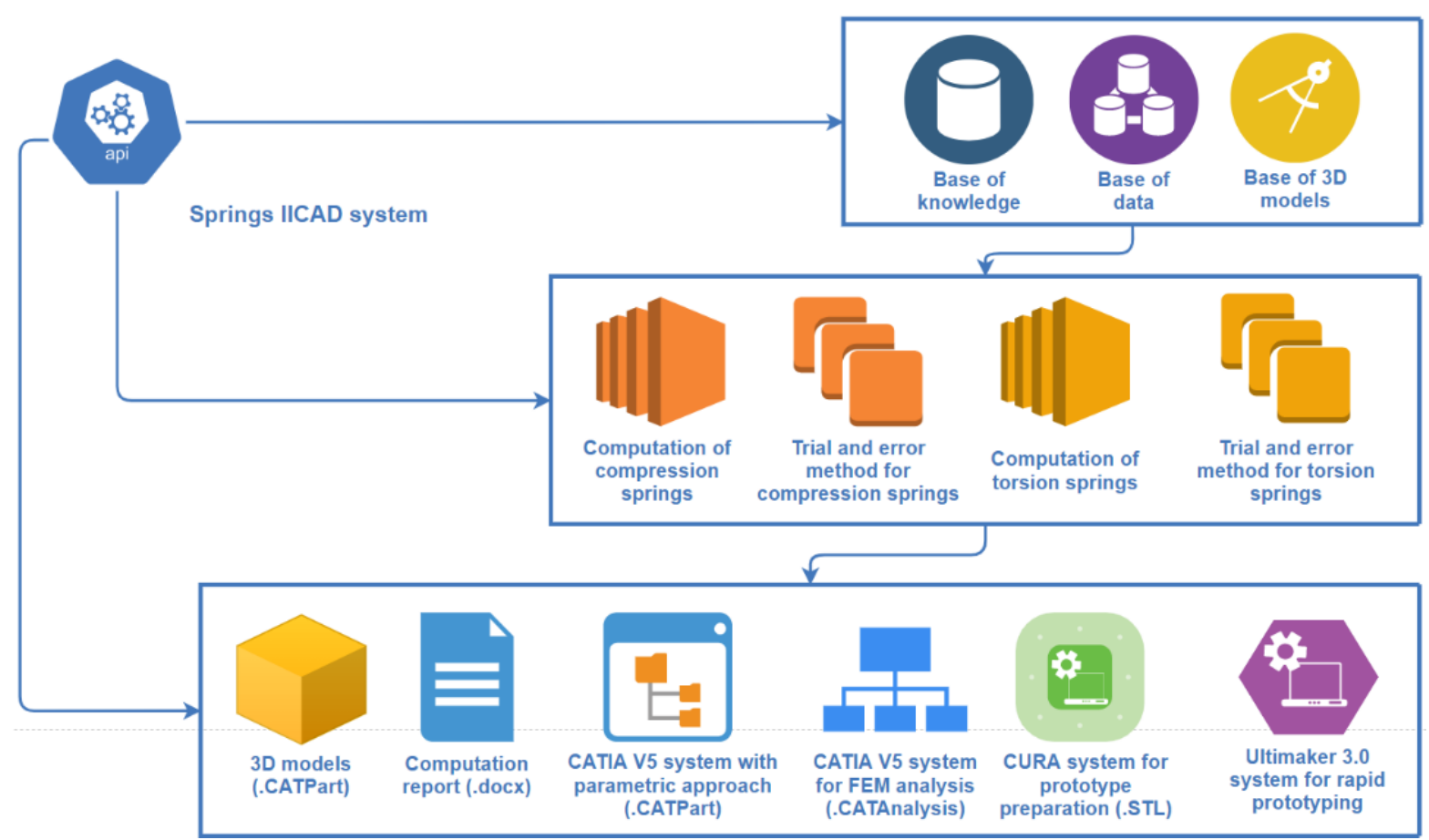

Figure 2. Springs IICAD system architecture.

\subsection{Design of the Springs IICAD System}

The system was designed and developed in the Microsoft's programming environment Visual Studio with the Windows Forms Application module, where background programming was realized with the C\# programming language. The Springs IICAD system was designed through multiple panels used to create a side menu from where four main forms may be accessed. Main forms represent the modules which include compression 
spring computation, compression spring trial and error method, torsion spring computation and torsion spring trial and error method. All of the system modules require input data, but there are slight differences in the manner of their use. Computing modules calculate the parameters for the new spring design, which are interlinked with the parametric 3D models, structural analysis files and prototype preparation environment through a set of specific buttons. Trial and error methods are used to check if the existing spring design will satisfy the working conditions. Standard spring arrangements are built-in into these modules, and with a few input parameters, a computation scan can be performed [30-32]. Trial and error modules are featured with the condition logs which prompt users if existing spring design is safe or not. Figure 3 shows the layout of the Springs IICAD system.

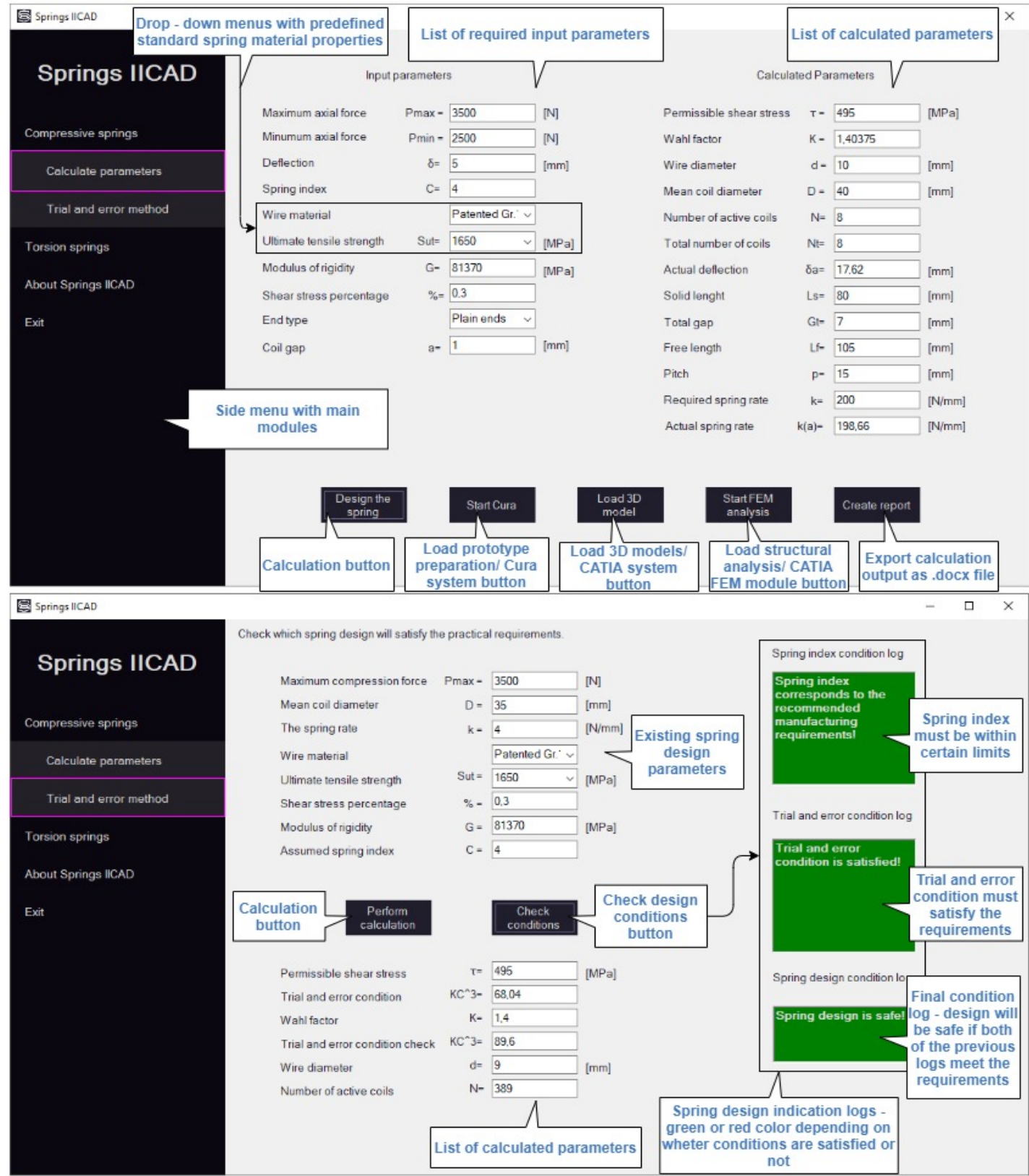

Figure 3. Interface layout of the Springs IICAD system (top to bottom: computation module and trial and error method module, respectively).

The standard built-in spring arrangements only consider the constant pitch values. The Springs IICAD system is built with a classic spring's requirements assumption, and it 
does not include the calculation of the unpredicted loads and dynamic conditions that may occur in the exploitation of the mechanism or the machine in which the springs are built in.

\subsection{Spring Materials}

The springs IICAD system has an incorporated database of the most extensively used materials for spring manufacturing as shown with the drop-down menus on Figure 3. One of those materials is a high-carbon drawn spring steel often referred to as a patented steel wire which has four grades. The selection of a certain material grade depends on the exploitation of the designed spring, i.e., a spring can be subjected to various load conditions, such as static, moderate, highly stress or dynamic loads. The second most commonly used material for the spring wires is unalloyed, oil-hardened spring wire with two grades, SW and VW, whose application is directed for fluctuating stress conditions. A drop-down menu for each of these materials and their grades contains the ultimate tensile strengths for these wires. The modulus of rigidity for these wire materials amounts to $81370 \mathrm{MPa}$, as shown in one of the input labels on Figure 3. Figure 4 shows the C\# code snippet used for the database programming.

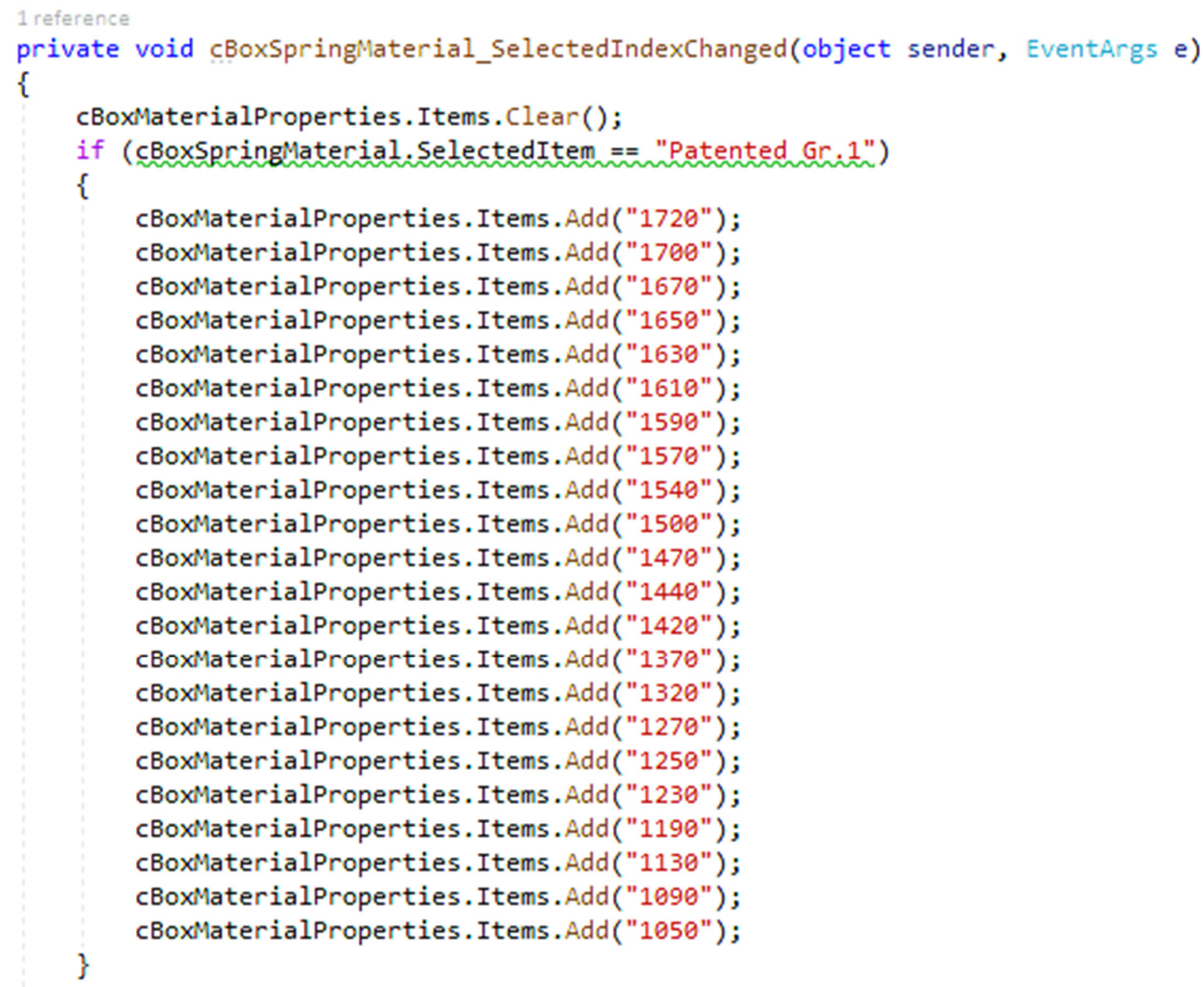

Figure 4. C\# code snippet used for the database programming (figure shows the ultimate tensile strengths for patented grade 1 spring wire which are available in user interface via simple if function implementation).

\subsection{Mathematical Models of Compression and Torsion Springs}

In a compression spring, the external force tends to shorten the spring, i.e., the spring is compressed. The external force acts along the axis of the spring and induces torsional 
shear stress in the spring wire. Although the spring is under compression, the wire of the spring is not subjected to compressive stress. Resultant stress, which includes direct shear stress, torsional shear stress and stress concentration due to curvature is given by:

$$
\tau=\frac{8 K P D}{\pi d^{3}}
$$

whereas:

$K$-stress factor or Wahl factor;

$P(\mathrm{~N})$ - external force;

$D(\mathrm{~mm})$ - mean coil diameter;

$d(\mathrm{~mm})$ - spring wire diameter. Wahl factor is given by:

$$
K=\frac{4 C-1}{4 C-4}+\frac{0.615}{C}
$$

whereas:

$C=D / d$-spring index.

Torsion springs transmit torque to a specific part in the mechanism in which they are applied. The torsion spring resists the bending moment, which tends to wind up the spring. Similar to the compression springs, the main term is misleading, because the spring wire is subjected to bending stresses. Induced bending stress is calculated as:

$$
\sigma_{b}=\frac{32 K_{i} M_{b}}{\pi d^{3}}
$$

whereas:

$K_{i}$-stress concentration factor at the inner fibers of the spring coil;

$M_{b}$ (Nmm)-bending moment;

$d(\mathrm{~mm})$-wire diameter.

With known material properties and housing dimensions in which the springs will operate, spring wire diameter can be expressed from the Equations (1) and (2). These equations are implemented into modules for computation of new spring design.

\subsection{Trial and Error Method}

In practice, springs are designed with the trial-and-error method. The trial-and-error method has several steps:

- Assume the spring dimensions (primarily wire diameter $d$ );

- Acquire ultimate tensile strength of the spring material and calculate permissible stress;

- Calculate induced stresses with the Equations (1) and (2);

- Examine if the permissible stress is greater than induced stress. If not, above steps should be repeated with the greater wire diameter;

- The procedure needs to be repeated until the value of induced stress is less than the value of the permissible stress.

The abovementioned procedure is built-in into trial-and-error modules for the compression and torsion springs. Once the input parameters are set, trial and error conditions are checked. For the compression springs, the trial-and-error method is based on calculating the value of required condition value:

$$
K C^{3}=\frac{\left(\pi D^{2} \tau\right)}{8 P}
$$

whereas:

$C=D / d$-spring index.

It is noticeable that Equation (3) is a different form of Equation (1), just expressed via the spring index. The value of $K C^{3}$ is calculated on the basis of material properties, i.e., permissible stress. This value is then compared with actual spring parameters, where the 
real $K C^{3}$ condition is computed. As long as the real condition value is lower than the required value, the spring design is not safe. For the torsion springs, the trial-and-error method uses a bit of a different approach. In this case, the trial-and-error method compares induced bending stress $\sigma_{b}$ with the permissible stress $\sigma_{t}$. The spring design will be safe if:

$$
\sigma_{b}<\sigma_{t}
$$

Apart from the mentioned conditions, the Springs IICAD system checks the values of the spring indexes. A spring index in a range of 4 to 12 is considered to be best for manufacturing purposes. When the spring index is low $(C<4)$, stresses in the spring wire will increase excessively due to the effect of curvature. When the spring index is high $(C>12)$, the spring may buckle and tangle during work operations. The trial-and-error modules of the developed Springs IICAD system have three condition logs which include spring index $\log$, trial-and-error log and spring design log. The spring design log informs the user if the spring design is safe or not, based on outputs of two other condition logs. The spring design is safe if both of the conditional logs are satisfied. Figure 5 shows a flowchart of the spring design condition log.

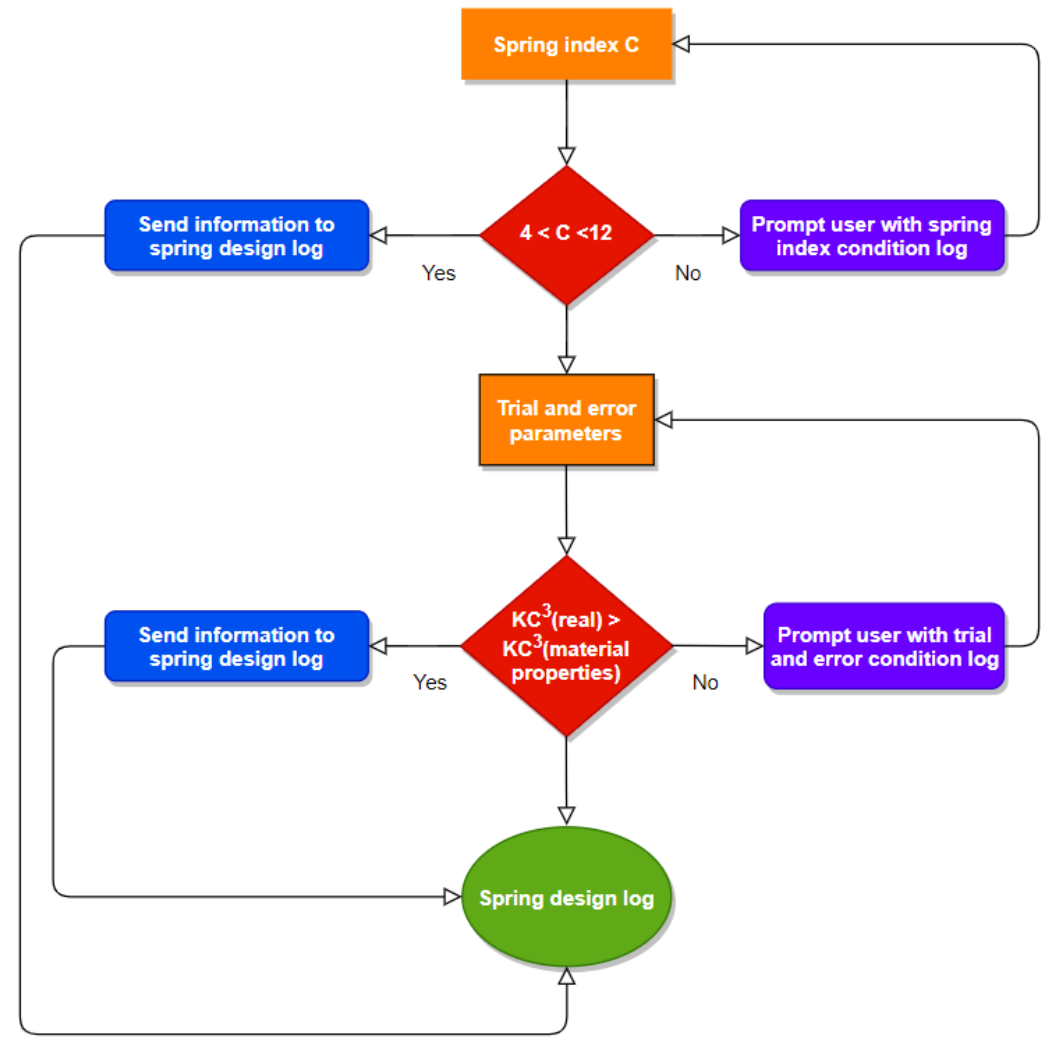

Figure 5. Condition log flowchart.

\subsection{Parametrization and Generation of the 3D Models}

The parametric modeling enables the creation of new design solutions based on previous designs. Because these modeling tools offer interoperability in a parametric manner, no model re-creation is necessary, giving the designer more time to explore a wider range of design alternatives [33-36]. The generated 3D models of the compression and torsion springs are completely parametrized and support automatic modification for all dimensions. Once the Springs IICAD modules for new spring design perform computations, the system is interlinked with CATIA software in which 3D models were made. This way parameters are automatically updated with output data values obtained from the developed system. Parameters which are formed both for compression and torsion springs include spring diameter, wire diameter, pitch value and number of revolutions. 
The torsion spring model has one additional parameter-length of free ends, as shown in Table 1.

Table 1. Compression and torsion spring design parameters.

\begin{tabular}{cccccc}
\hline $\begin{array}{c}\text { Developed } \\
\text { Parameters/ } \\
\text { Spring Type }\end{array}$ & $\begin{array}{c}\text { Number of } \\
\text { Revolutions } \\
(-)\end{array}$ & $\begin{array}{c}\text { Pitch Value } \\
\text { (mm) }\end{array}$ & $\begin{array}{c}\text { Spring } \\
\text { Diameter } \\
\text { (mm) }\end{array}$ & $\begin{array}{c}\text { Wire } \\
\text { Diameter } \\
\text { (mm) }\end{array}$ & $\begin{array}{c}\text { Length of } \\
\text { Free Ends } \\
\text { (mm) }\end{array}$ \\
\hline Compression & $\checkmark$ & $\checkmark$ & $\checkmark$ & $\checkmark$ & $\boldsymbol{x}$ \\
Torsion & $\checkmark$ & $\checkmark$ & $\checkmark$ & $\checkmark$ & $\checkmark$ \\
\hline
\end{tabular}

\subsection{Spring Model Configurations}

In addition to the manipulation of the basic geometric parameters, Springs IICAD system enables the user to choose between multiple spring type configurations, i.e., styles of end.

There are four common methods, both for compression and torsion springs, in which the ends can be formed. For the compression springs, the end styles are: plain, plain and ground, square, square and ground. Torsion springs have the following end styles: $90^{\circ}$ $180^{\circ}, 270^{\circ}$ and $360^{\circ}$. Accordingly, eight models were developed, all with the mentioned parameters, just with differences in the end styles. Once the user selects the preferred end style from the offered drop-down list and performs the calculation, the Springs IICAD system will change the parameters of the model. Standard-end style arrangements for compression and torsion springs are shown on Figure 6.

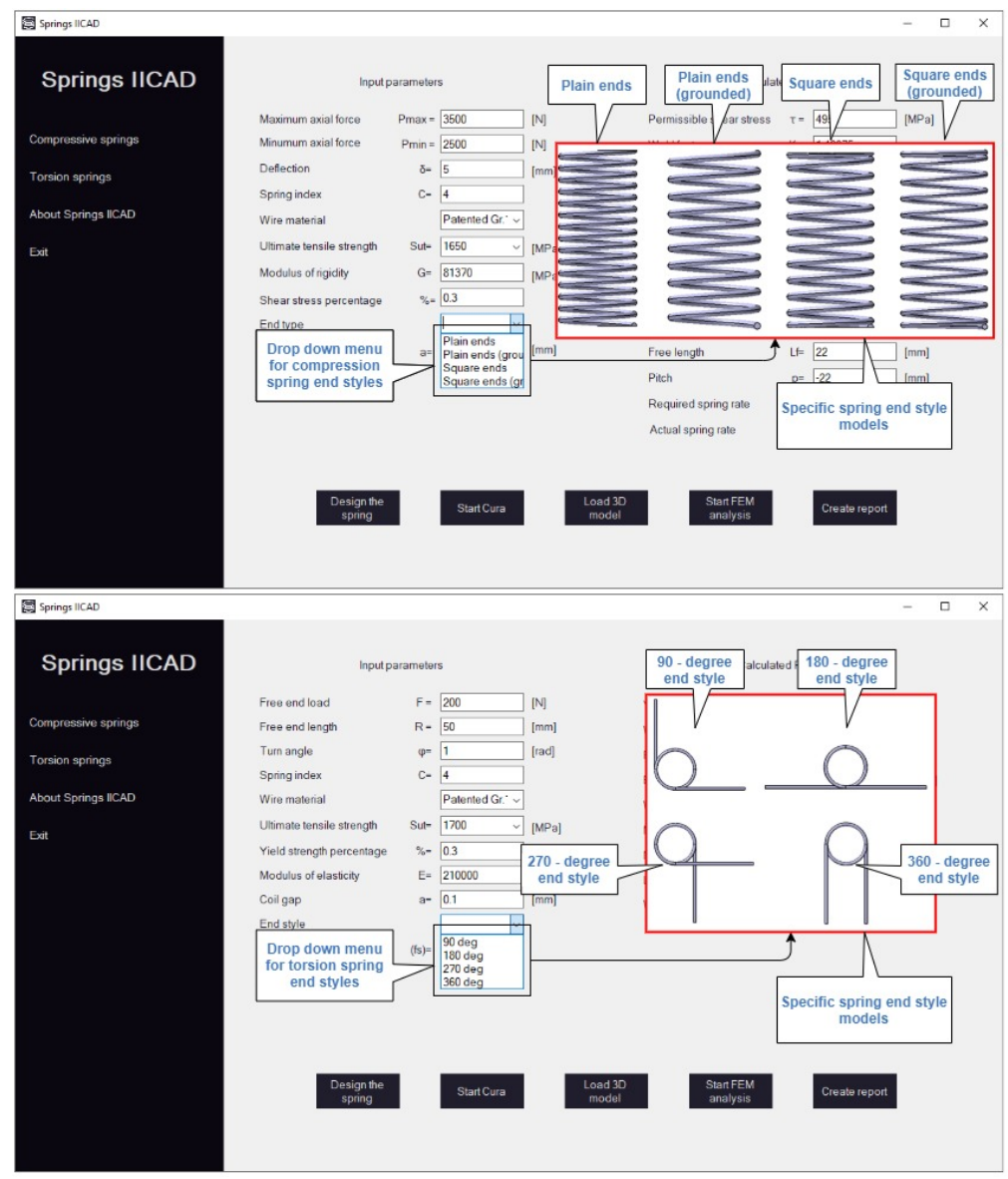

Figure 6. Possible spring model generation outputs based on the end styles (top to bottom: compression spring end styles and torsion spring end styles, respectively). 


\section{Results}

\subsection{FEM Analysis Results}

The finite element method simulates a physical part or assembly's behavior by dividing the geometry of the part into a number of elements of standard shapes, applying loads and constrains, then calculating variables of interest [37-40]. Numerical methods, such as the finite element method, have been applied in various researches in order of achieving such a spring design that eliminates the limitations of the theoretical and experimental methods in the calculation and measurement of the maximum stress in the different sections of the spring [41]. Springs IICAD modules support the FEM analysis. With the purposely made buttons, the user can easily access FEM analysis files of the computed/ designed spring. Boundary conditions of the compression spring FEM models are predefined in the CATIA software, with a clamp applied on the bottom surface of the spring and user defined restrain which simulates only the vertical spring movement. This way, the spring housing is simulated. For the torsion spring, similarly, one of the free ends is clamped, while the other end is loaded with the distributive force. The parametric approach of 3D modeling was interlinked with the Springs IICAD system, so with an input of any geometric parameter, material property and force, changes are made in the specific files. When input parameters are set in the Springs IICAD system and the calculation button is activated, spring geometry is updated in the 3D model file, based on the input of geometric parameters. An FEM analysis file follows these geometric updates and includes a specified load and material property defined in the Spring IICAD system. This way, a spring FEM model is processed where it originates from its initial state, and under specified force, geometry and mechanical properties, a load state occurs followed with the stress and deflection images. Meshing is performed via a uniform grid with the parabolic tetrahedron finite elements (TE10) since they are more accommodating for the curved surfaces. The mesh size and absolute sag, for both types of springs, amount to $0.2 \mathrm{~mm}$ and $0.1 \mathrm{~mm}$, respectively. The number of finite elements and nodes used for discretization of a spring model depends on the spring parameters, since the parametric approach can result in many design solutions. Table 2 shows the number of finite elements and nodes generated for specific spring design, with the following sizes for the compression spring: number of revolutions-10, pitch-4 mm, mean coil diameter $-20 \mathrm{~mm}$, wire diameter $-2 \mathrm{~mm}$; and for the torsion spring: number of revolutions -25 , pitch $-2 \mathrm{~mm}$, mean coil diameter-28 $\mathrm{mm}$, wire diameter-1.8 $\mathrm{mm}$, and length of free ends- $50 \mathrm{~mm}$. Figure 7 shows the Von Mises stress distribution and displacement for the specific set of parameters of a compression spring.

Table 2. Number of finite elements and nodes for specific spring design.

\begin{tabular}{ccc}
\hline $\begin{array}{c}\text { Mesh Property/ } \\
\text { Spring Type }\end{array}$ & Number of Finite Elements & Number of Nodes \\
\hline Compression & 17,213 & 34,414 \\
Torsion & 60,428 & 12,0947 \\
\hline
\end{tabular}

Maximum Von Mises stress according to colormap shown in Figure 7 is located at the "crossing zone" between the plain end and the first coil of the spring. This stress spike is caused with the stress concentration. However, maximum working stresses occur on the inner side of the spring coil, which is a result of the uneven stress distribution due to a wire twist. The maximum deflection of a compression spring is located at the top coil, i.e., the load zone of the spring. Figure 8 shows the Von Mises stress distribution and displacement for the specific set of parameters of a torsion spring. Maximum Von Mises stress is located at the fixed end of the torsion spring. This stress is also caused with the stress concentration. Maximum working stresses occur in a different location of a spring wire due to complex stress conditions, i.e., the simultaneous effect of the bending moment and the spring wind. Maximum deflection is located at the loaded end of the spring. Alongside the fast manipulation of geometric parameters and easy insight into stress and deflection conditions, the significance of FEM analysis is best reflected in the 
determination of the strength criterium for the developed spring, meaning a compression spring needs to satisfy the permissible shear stress condition and a torsion spring needs to satisfy the permissible bending stress condition.

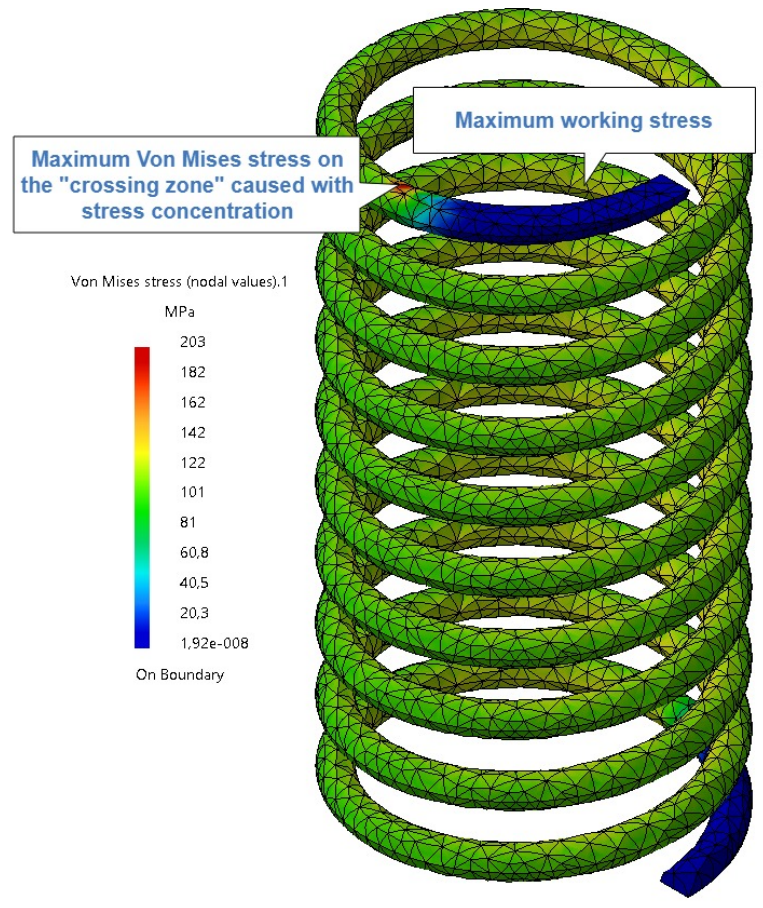

a)

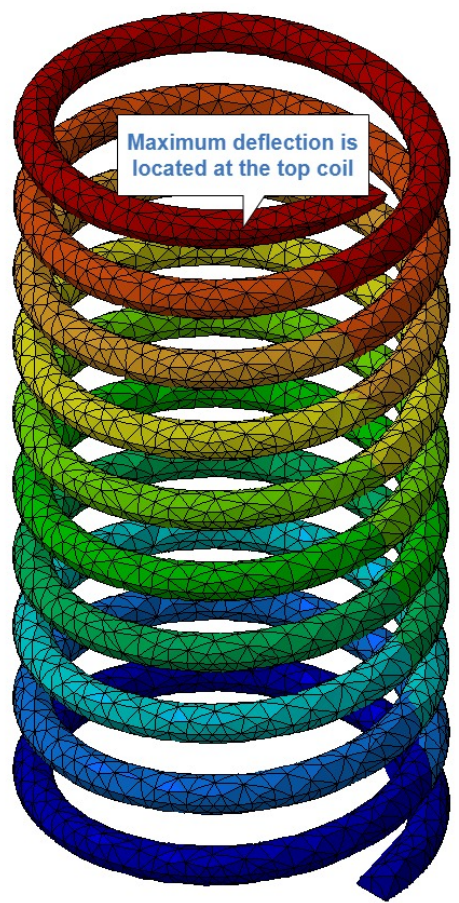

b)

Figure 7. Compression spring with plain ends FEM analysis results. (a): Von Mises tress, (b): Displacement.

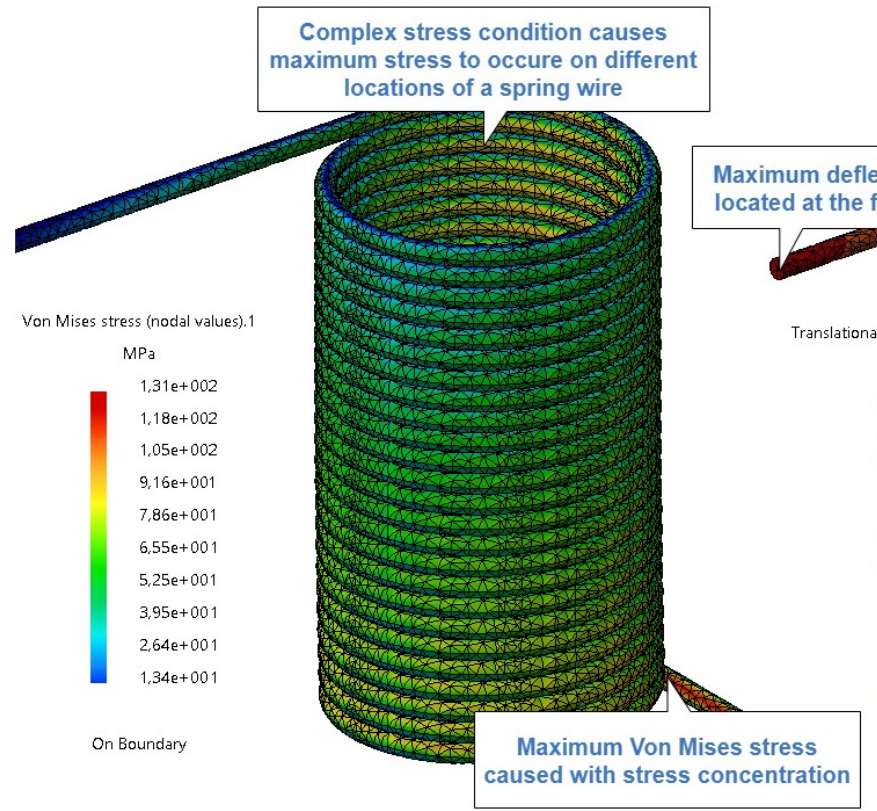

a)

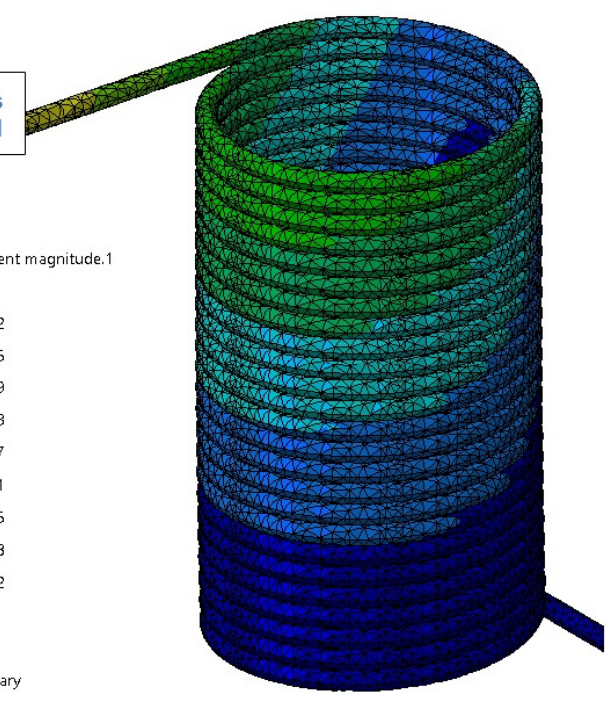

b)

Figure 8. $90^{\circ}$ end type torsion spring FEM analysis results. (a): Von Mises stress, (b): Displacement.

\subsection{Physical Prototypes}

The prototype model is an important tool and achievement in model designing, producing and testing, as it shows and reflects the quality of many aspects concurrently, 
such as materials, processing technology, functionality, performance and modeling, so the planning of the prototype model which almost collects all the design results and goals is very important for validation, evaluation, and decision value on product testing and development [42-44]. During the development of the Springs IICAD system, one of the focuses was to link system with the RP (rapid prototyping) devices. The system is interlinked with the Cura software, where 3D models of the springs are prepared for 3D printing with the Ultimaker 3.0 printer. Physical prototypes of the springs were printed with the PLA (polylactic acid) material. PLA spring prototypes are used for the additional spring design check, i.e., visual inspection regarding only spring geometry, since PLA prototypes have much lower mechanical properties compared to metal. Although the developed system in its current form supports only the specified 3D printer, this feature gives a projection to a future development of a manufacturing process which includes metal 3D printing, whose implementation would be achieved in the same manner. Figure 9 shows a spring schematic representation of a prototyping procedure implemented via developed system.

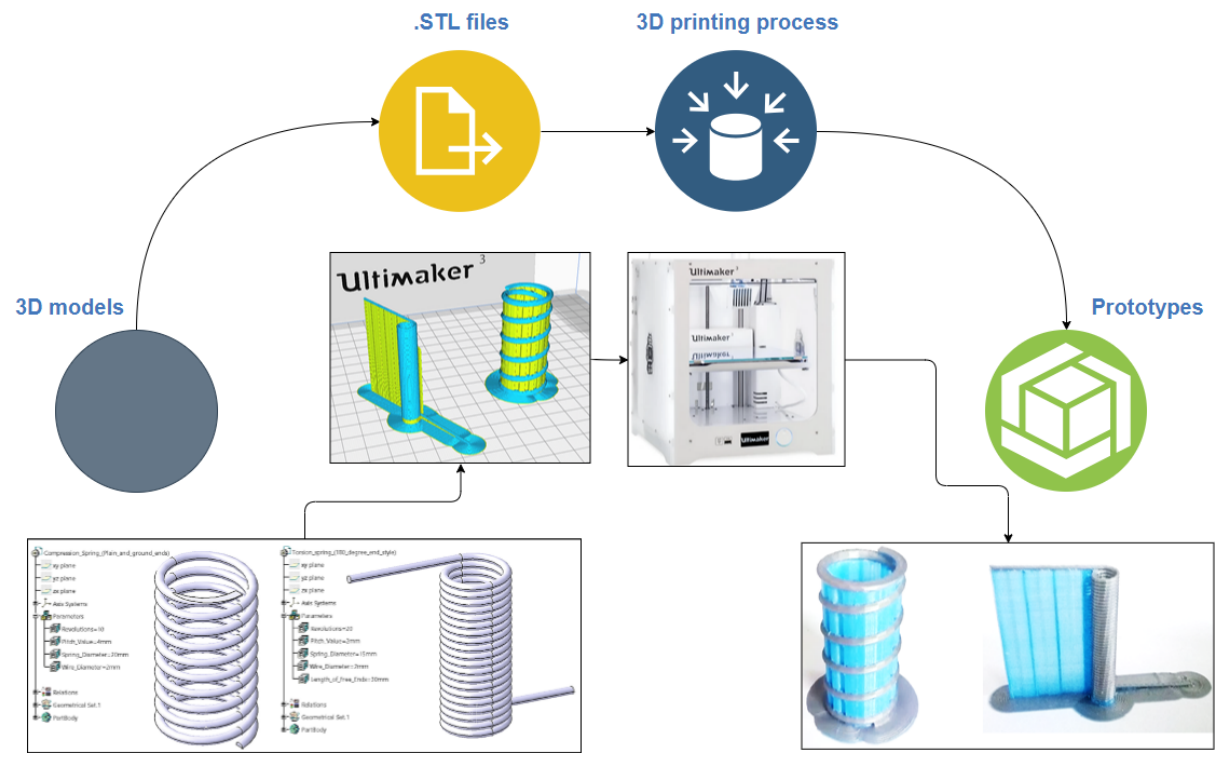

Figure 9. Schematic representation of a spring prototyping procedure (features implemented through Springs IICAD system).

\subsection{Output Data Report Generation}

Computation modules of the Springs IICAD system also enables users to generate reports of the output data. Reports are generated in the form of the .docx files, where complete set of input and corresponding output parameters are listed. In order to create such a feature, it is necessary to add a Microsoft Word Object Library reference from the Visual Studio settings. Once the reference is added, the function named "documentWritter" is created. A piece of the C\# code for this function is shown on Figure 10. The values of the input and output parameters, which the function will export are simply implemented through a button click event. 


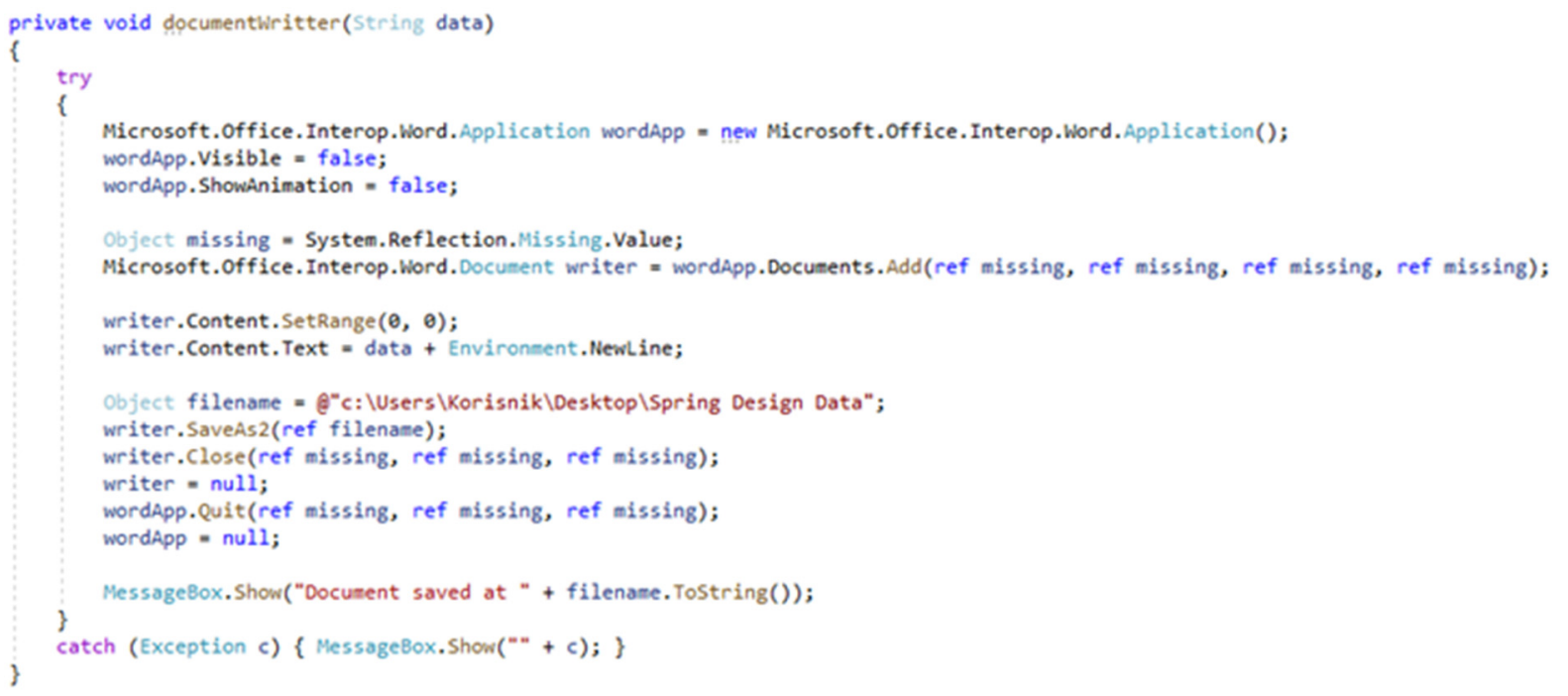

Figure 10. C\# code for the "documentWriter" function.

\section{Conclusions}

The implementation of the intelligent approach into a design process helps designers and engineers to solve various problems faster and more efficiently. The developed Springs IICAD system links the spring design modules directly with the parametric 3D models, FEM analysis, prototype preparation and rapid prototyping. Unlike the traditional design process, which can be exhausting and time consuming, the presented approach results in better judgement of the design process. With usage of such an approach, the design process is less affected by the subjectivity of a designer which can lead to a poor design and lower product quality. With information provided by a developed system and data obtained from the interlinked FEM analysis module, the designer is less susceptible to errors due to design prompts integrated into the system, and easily accessible data and graphical representation.

Alongside the proper knowledge of a specific thematic and programming logic necessary to develop a functional system, it is vital to know the features of an IDE (integrated development environment) which can be used to solve specific problem efficiently, as in the case of data report. Although, much effort needs to be put into a development of the described intelligent system, all of the mentioned positive effects and benefits give the conclusion that the development of the described system is completely justified, especially in the conditions of the high-rate productions, where the implementation of an integrated intelligent CAD system would be a profitable investment in the long run.

There is a lot of scope for further research in this topic. First of all, an expanded spring system which will support experimental study of specific spring characteristics. Considering that current version of the developed system supports only compression and torsion springs, further improvements should be directed to creating new modules for the other classical spring forms and the unconventional forms which are in use. Additionally, an expansion considering variable spring pitch should be included. Further research should also consider developing an optimization process for spring geometry and correction factors which would improve spring functionality under a certain load condition.

Author Contributions: Conceptualization, I.S.; methodology, A.M.; investigation, E.M. (Enis Muratovi) and M.D.; data curation, N.P. and M.C.; software, E.M. (Enis Muratovic); visualization, E.M. (Elmedin Mesic); writing—original draft preparation, E.M. (Enis Muratovic); writing—review and editing, A.J.M. All authors have read and agreed to the published version of the manuscript.

Funding: This research received no external funding.

Informed Consent Statement: Not applicable. 
Data Availability Statement: The data underlying this study will be available on reasonable request to the corresponding author.

Conflicts of Interest: The authors declare no conflict of interest.

\section{References}

1. Wu, L.; Chen, L.; Fu, H.; Jiang, Q.; Wu, X.; Tang, Y. Carbon fiber composite multistrand helical springs with adjustable spring constant: Design and mechanism studies. J. Mater. Res. Technol. 2020, 9, 5067-5076. [CrossRef]

2. Takahashi, T.; Zehnder, J.; Okuno, H.G.; Sugano, S.; Coros, S.; Thomaszewski, B. Computational Design of Statically Balanced Planar Spring Mechanisms. IEEE Robot. Autom. Lett. 2019, 4, 4438-4444. [CrossRef]

3. Ke, J.; Wu, Z.Y.; Liu, Y.S.; Xiang, Z.; Hu, X.D. Design method, performance investigation and manufacturing process of composite helical springs: A review. Compos. Struct. 2020, 252, 112747. [CrossRef]

4. Nazir, A.; Ali, M.; Hsieh, C.H.; Jeng, J.Y. Investigation of stiffness and energy absorption of variable dimension helical springs fabricated using multijet fusion technology. Int. J. Adv. Manuf. Technol. 2020, 110, 2591-2602. [CrossRef]

5. Zebdi, O.; Boukhili, R.; Trochu, F. Optimum design of a composite helical spring by multi-criteria optimization. J. Reinf. Plast. Compos. 2009, 28, 1713-1732. [CrossRef]

6. Kobelev, V. Elastic-plastic deformation and residual stresses in helical springs. Multidiscip. Model. Mater. Struct. 2020, 16, 448-475. [CrossRef]

7. Wan, J.; Li, J.; Hua, Q.; Celesti, A.; Wang, Z. Intelligent equipment design assisted by Cognitive Internet of Things and industrial big data. Neural Comput. Appl. 2020, 32, 4463-4472. [CrossRef]

8. Belman-Lopez, C.E.; Jiménez-García, J.A.; Hernández-González, S. Comprehensive analysis of design principles in the context of Industry 4.0. Rev. Iberoam. Automática Inf. Ind. 2020, 17, 432-447. [CrossRef]

9. Patel, A.R.; Ramaiya, K.K.; Bhatia, C.V.; Shah, H.N.; Bhavsar, S.N. Artificial Intelligence: Prospect in Mechanical Engineering Field-A Review. In Data Science and Intelligent Applications; Lecture Notes on Data Engineering and Communications Technologies; Springer: Singapore, 2021; Volume 52, pp. 267-282.

10. Saric, I.; Muminovic, A.; Colic, M.; Rahimic, S. Development of integrated intelligent computer-aided design system for mechanical power-transmitting mechanism design. Adv. Mech. Eng. 2017, 9, 1687814017710389. [CrossRef]

11. Novak, M.; Dolšak, B. Intelligent FEA-based design improvement. Eng. Appl. Artif. Intell. 2008, 21, 1239-1254. [CrossRef]

12. Bulut Özek, M.; Akpolat, Z.H.; Orhan, A. A web-based intelligent tutoring system for a basic control course. Comput. Appl. Eng. Educ. 2013, 21, 561-571. [CrossRef]

13. Saric, I.; Pervan, N.; Muminovic, A.; Colic, M. Development of integrated intelligent cad system for design of shafts. Teh. Vjesn. 2018, 25, 99-104.

14. Klancnik, S.; Brezocnik, M.; Balic, J. Intelligent CAD/CAM system for programming of CNC machine tools. Int. J. Simul. Model. 2016, 15, 109-120. [CrossRef]

15. Valles González, M.P.; García-Martínez, M.; Pastor Muro, A. Study of a torsion spring fracture. Eng. Fail. Anal. 2019, 98, 150-155. [CrossRef]

16. Yang, C.J.; Zhang, W.H.; Ren, G.X.; Liu, X.Y. Modeling and dynamics analysis of helical spring under compression using a curved beam element with consideration on contact between its coils. Meccanica 2014, 49, 907-917. [CrossRef]

17. Zhang, P.; Wang, D.; Guo, Y.; Cheng, P.; Shao, C.; Lang, N.; Liu, X.; Huang, J. Fatigue failure analysis and finite element assessment of the twins torsion spring. Eng. Fail. Anal. 2021, 122, 105187. [CrossRef]

18. Kumar, K.; Aggarwal, M.L. Finite element analysis and optimization of a mono parabolic leaf spring using cae software. Eng. Solid Mech. 2015, 3, 85-92. [CrossRef]

19. Song, X.; Li, B.H.; Chai, X. Research on key technologies of complex product virtual prototype lifecycle management (CPVPLM). Simul. Model. Pract. Theory 2008, 16, 387-398. [CrossRef]

20. Mykhaskiv, O.; Banović, M.; Auriemma, S.; Mohanamuraly, P.; Walther, A.; Legrand, H.; Müller, J.D. NURBS-based and parametric-based shape optimization with differentiated CAD kernel. Comput.-Aided Des. Appl. 2018, 15, 916-926. [CrossRef]

21. Chandravanshi, M.L.; Mukhopadhyay, A.K. Analysis of variations in vibration behavior of vibratory feeder due to change in stiffness of helical springs using FEM and EMA methods. J. Braz. Soc. Mech. Sci. Eng. 2017, 39, 3343-3362. [CrossRef]

22. Tan, P.S.; Farid, A.A.; Karimzadeh, A.; Rahimian Koloor, S.S.; Petrů, M. Investigation on the curvature correction factor of extension spring. Materials 2020, 13, 4199. [CrossRef] [PubMed]

23. Kreis, A.; Walzel, B.; Schäfer, U.; Hirz, M. Onsite medical implants creation by combination of enhanced design methods and 3d printing. Comput. Aided. Des. Appl. 2022, 19, 336-345. [CrossRef]

24. Mandičák, T.; Behúnová, A.; Mésároš, P.; Knapčíková, L. Current state of knowledge-based systems used in architecture, engineering and construction. TEM J. 2020, 9, 716-721. [CrossRef]

25. Zheng, C.; Xing, J.; Wang, Z.; Qin, X.; Eynard, B.; Li, J.; Bai, J.; Zhang, Y. Knowledge-based program generation approach for robotic manufacturing systems. Robot. Comput. Integr. Manuf. 2022, 73, 102242. [CrossRef]

26. Guo, L.; Yan, F.; Li, T.; Yang, T.; Lu, Y. An automatic method for constructing machining process knowledge base from knowledge graph. Robot. Comput. Integr. Manuf. 2022, 73, 102222. [CrossRef] 
27. Aztiria, A.; Augusto, J.C.; Basagoiti, R.; Izaguirre, A.; Cook, D.J. Discovering frequent user-environment interactions in intelligent environments. Pers. Ubiquitous Comput. 2012, 16, 91-103. [CrossRef]

28. Sha, W.; Guo, Y.; Yuan, Q.; Tang, S.; Zhang, X.; Lu, S.; Guo, X.; Cao, Y.-C.; Cheng, S. Artificial Intelligence to Power the Future of Materials Science and Engineering. Adv. Intell. Syst. 2020, 2, 1900143. [CrossRef]

29. Ali, H.; Albagul, A.; Algitta, A. Optimization of Pid Parameters Based on Particle Swarm Optimization for Ball and Beam System. Int. J. Eng. Technol. Manag. Res. 2020, 5, 59-69. [CrossRef]

30. Ghionea, I.G.; Devedžić, G.; Ćuković, S. Parametric Modeling of Surfaces Using CATIA v5 Environment. Appl. Mech. Mater. 2015, 760, 93-98. [CrossRef]

31. Xu, S.; Timme, S.; Mykhaskiv, O.; Müller, J.D. Wing-body junction optimisation with CAD-based parametrisation including a moving intersection. Aerosp. Sci. Technol. 2017, 68, 543-551. [CrossRef]

32. Wang, C.; Wen, C.; Dai, Y.; Yu, S.; Liu, M. Urban 3D modeling with mobile laser scanning: A review. Virtual Real. Intell. Hardw. 2020, 2, 175-212. [CrossRef]

33. Tian, C. 3D modeling and digital preservation of ancient architectures based on autoCAD and 3Dmax. Comput. Aided. Des. Appl. 2020, 17, 100-110. [CrossRef]

34. Nabagło, T.; Jurkiewicz, A.; Kowal, J. Modeling verification of an advanced torsional spring for tracked vehicle suspension in 2S1 vehicle model. Eng. Struct. 2021, 229, 111623. [CrossRef]

35. Calaf-Chica, J.; Bravo Díez, P.M.; Preciado Calzada, M.; Ballorca-Juez, D. A systematic FEM analysis of the influence of mechanical properties in the reliability of the correlation methods in the small punch test. Int. J. Mech. Sci. 2019, 153-154, 299-309. [CrossRef]

36. Bertrand, C.; Acary, V.; Lamarque, C.H.; Ture Savadkoohi, A. A robust and efficient numerical finite element method for cables. Int. J. Numer. Methods Eng. 2020, 121, 4157-4186. [CrossRef]

37. Carbonell, J.M.; Rodríguez, J.M.; Oñate, E. Modelling 3D metal cutting problems with the particle finite element method. Comput. Mech. 2020, 66, 603-624. [CrossRef]

38. Berman, B. 3-D printing: The new industrial revolution. Bus. Horiz. 2012, 55, 155-162. [CrossRef]

39. Cao, D.X.; Fu, M.W. A knowledge-based prototype system to support Product Conceptual Design. Comput. Aided. Des. Appl. 2011, 8, 129-147. [CrossRef]

40. Singer, G.; Golan, M.; Cohen, Y. From product documentation to a method prototype and standard times: A new technique for complex manual assembly. Int. J. Prod. Res. 2014, 52, 507-520. [CrossRef]

41. Ribeiro, D.; Cimino, S.R.; Mayo, A.L.; Ratto, M.; Hitzig, S.L. 3D printing and amputation: A scoping review. Disabil. Rehabil. Assist. Technol. 2021, 16, 221-240. [CrossRef]

42. Cai, G.; Cheng, X.; Wang, D. Preparation of 316L Stainless Steel Products by Fused Deposition Model 3D-printing and Effect of La on Morphology and Distribution of Precipitates. Cailiao Yanjiu Xuebao/Chin. J. Mater. Res. 2020, 34, 635-640.

43. Belov, V.F.; Gavryushin, S.S.; Markova, Y.N. A Mathematical Model of Distributed Prototype Design in Mechanical Engineering Proc. High. Educ. Inst. Machine Build. 2019, 9, 7-19. [CrossRef]

44. Eren, N.; Brunesi, E.; Nascimbene, R. Influence of masonry infills on the progressive collapse resistance of reinforced concrete framed buildings. Eng. Struct. 2019, 178, 375-394. [CrossRef] 